\title{
Effects of some flavonoids on the mycotoxin citrinin reduction by Monascus aurantiacus Li AS3.4384 during liquid-state fermentation
}

Yanling Wang ${ }^{1,2}$, Heng Gao ${ }^{1,2}$, Jianhua Xie ${ }^{1}$, Xiujiang $\mathrm{Li}^{3}$ and Zhibing Huang ${ }^{1,2^{*}}$ (1)

\begin{abstract}
Monascus can produce many beneficial metabolites; however, it can simultaneously also produce citrinin, which seriously limits its application. Therefore, reducing the production of citrinin is of great interest. Herein, Monascus aurantiacus Li AS3.4384 (MAL) was used to optimize the liquid-state fermentation process and investigate the effects of genistein and other flavonoids on citrinin, pigments, and biomass of MAL. Results showed that citrinin decreased by $80 \%$, pigments and biomass increased by approximately $20 \%$ in 12 days with addition of $20.0 \mathrm{~g} / \mathrm{L}$ rice powder as a carbon source and $2.0 \mathrm{~g} / \mathrm{L}$ genistein during shaking liquid-state fermentation. Further, genistein, daidzein, luteolin, apigenin, quercetin, baicalein, kaempferol myricetin, and genistin exerted different effects on citrinin production by MAL, with genistein causing the highest reduction in citrinin production during liquid-state fermentation, possibly due to the presence of $\mathrm{C} 5-\mathrm{OH}, \mathrm{C} 4^{\prime}-\mathrm{OH}$, and $\mathrm{C} 7-\mathrm{OH}$. Therefore, genistein can be added to the fermentation process of Monascus to reduce citrinin.
\end{abstract}

Keywords: Monascus, Citrinin, Pigment, Genistein, Flavonoids

\section{Introduction}

Since the era of Tang Dynasty (618-907 AD), Monascus has been used in China to produce sufu, wine, and colorants. Currently, Monascus is widely used in the fields of food, medicine and health care (Chen et al. 2017; Huang et al. 2019). Monascus can produce many useful secondary metabolites, such as Monascus pigments, Monacolin $\mathrm{K}$, ergosterol, $\gamma$-aminobutyric acid, and unsaturated fatty acids (Akilandeswari and Pradeep 2016; Hilares et al. 2018; Li et al. 2019; Zhang et al. 2019; Gomes and Takahashi 2016). Monascus pigments have long been used as natural food additives, particularly in China, Japan, and other Southeast Asian countries (Dufosse 2018; Chen et al. 2015; Hajjaj et al. 1999). Monascus pigment is a mixture of polyketones belonging to the following three

\footnotetext{
*Correspondence: hzbchem@ncu.edu.cn

1 State Key Laboratory of Food Science and Technology, Nanchang

University, No. 235 Nanjing East Road, Nanchang 330047, China

Full list of author information is available at the end of the article
}

main pigments: red, orange, and yellow. Further, the six main pigment components include rubropunctamine and monascorubramine (red pigment), rubropunctatin and monascorubrin (orange pigment), and monascin and ankaflavin (yellow pigment) (Balakrishnan et al. 2013; Yongsmith et al. 2013; Lu et al. 2018; Schweiggert 2018; Lv et al. 2018). Studies have shown that some Monascus pigments also possess anti-inflammatory, anti-atherosclerosis, anti-cancer, anti-bacterial, and potential antiobesity properties (Xu et al. 2018; Orak et al. 2018; Zheng et al. 2016).

Monascus secretes beneficial secondary metabolites while also producing a potentially toxic secondary metabolite, citrinin (Nigović et al. 2013). Citrinin is a mycotoxin of polyketides, and its main targeting organ is kidney. Reportedly, $50 \mu \mathrm{mol} / \mathrm{L}$ of citrinin can deregulate calcium homeostasis of PK15 cells, leading to cell death (Rumora et al. 2014). In the kidney and liver mitochondria, citrinin can inhibit activities of oxidoreductases and ATPases, interfere with the electron transport chain, reduce the 
efficiency of mitochondrial phosphorylation, and change the transmembrane potential, resulting in decreased intracellular respiratory efficiency. Protease activity is also blocked by citrinin. Thus, it seriously affects human health and hinders the development of Monascus products (Liao et al. 2014; Gayathri et al. 2015).

As a result, there is an urgent need to study methods to reduce citrinin production by Monascus spp. There are currently three approaches to investigate citrinin production. Firstly, a mutant strain can be generated to produce low-yield or non-producing citrinin-resistant strains (Dikshit and Tallapragada 2018). Jia et al.(2010) used traditional physical chemical mutagenesis and metabolic engineering methods to obtain a citrinin-free mutant of the gene $p k s C T$, thereby obtaining a strain that does not produce citrinin. Secondly, medium optimization can reduce the yield of citrinin ( $\mathrm{Hu}$ et al. 2016). Carels and Shepherd (1977) explored the effects of carbon source and nitrogen sources on citrinin and pigment. Wong et al. (1981) studied the effect of the carbon/nitrogen ratio on citrinin levels in the medium. Kang et al. (2014) proposed a method to reduce citrinin production and increase the yield of yellow pigment under low $\mathrm{pH}$ conditions. Tsukahara et al. (2009) have reported that increasing culture temperature can effectively increase the yield of pigment and reduce citrinin. Wan et al. (2017) proposed that citrinin production could be affected under a low frequency magnetic field. Thirdly, genetic engineering has been used recently to knock out key genes to reduce citrinin. Shimizu et al. (2007) significantly reduced citrinin production by knocking out the $\operatorname{ctn} A$ gene in the flanking region of the $p k s C T$ gene.

Flavonoids are a class of compounds with a flavone structure. Flavonoids are mostly crystalline solids, with few as amorphous powders (Echeverry et al. 2010). They are widely distributed in the plant kingdom, and the fruits and vegetables that are consumed daily are rich in flavonoids. Although there are many kinds of flavonoids, their main structure is composed of two aromatic rings connected by an oxygen-containing heterocyclic ring (Fig. 1a). According to the difference of the substituents on the mother nucleus and the connection position of the $B$ ring, the flavonoids can be divided into six categories: flavonols such as quercetin, myricetin, and kaempferol; flavonoids such as luteolin and baicalein; flavanols such as catechins; flavanones such as naringenin; anthocyanins, and isoflavones such as genistein (Wolfe and Liu 2008; Olagaray and Bradford 2019). Genistein is considered a preventive drug that can prevent various diseases, including cancer, postmenopausal bone loss, and cardiovascular disease. It is the most abundant isoflavone in soybean and has been reported to function as a protein tyrosine Kinase
(PTK) inhibitor. It is also believed to becoming effective against antioxidants, to have anti-proliferative and anti-skin cancer functions, and to regulate estrogen function (Kundu et al. 2018; Wang et al. 2019; Fan et al. 2019). Flavonoids have a variety of active functions such as anticancer, antioxidative, antimicrobial, and anti-inflammation (Cheng et al. 2011; Li et al. 2008; Fang et al. 2016; Benavente-García and Castillo 2008).

In the current study, we investigated the effects of several flavonoids on the metabolites produced by Monascus aurantiacus Li AS3.4384 (MAL) during liquid medium fermentation. Further, we analyzed the activity and structure-activity relationship between the flavonoids and metabolites secreted by MAL.

\section{Materials and methods}

\section{Materials, fungal strains, and apparatus}

MAL, a high producer of citrinin, was purchased from the Microbial Preservation Center (Beijing, China). Flavonoids, including genistein (purity 97\%), daidzein (purity $\geq 98 \%$ ), genistin (purity $\geq 95 \%$ ), myricetin (purity 97\%), and luteolin (purity $\geq 98 \%$ ), were obtained from Aladdin Reagent Co. Ltd (Shanghai, China). Apigenin (purity $\geq 97 \%$ ), baicalein (purity 98\%), quercetin (purity 97\%), and kaempferol (purity 97\%) were purchased from Shanghai Macklin Biochemical Technology Co., Ltd (Shanghai, China). Pearl rice (produced in Heilongjiang) was obtained from a local supermarket. After grinding, the rice powder was filtered through a 100 mesh sieve. Methanol, acetonitrile (HPLC grade), and other reagents (analytical grade) were purchased from Aladdin Reagent Co., Ltd. (Shanghai, China). A spectrophotometer was purchased from Thermo Fisher Scientific (Oy Ratastie 2, FI-01620 Vantaa, Finland). KDC-140HR highspeed refrigerated centrifuge was obtained from Anhui Zhongke Zhongjia Scientific Instrument Co., Ltd. (Hefei, China). ZWY-2102C constant-temperature culture oscillators were purchased from Shanghai ZHICHENG Analytical Instrument Co., Ltd. (Shanghai, China). Electric thermostat blast drying oven was obtained from Huangshi Hengfeng Medical Instrument Co., Ltd. (Huangshi, China). Agilent 1260 high-performance liquid chromatography system equipped with an automatic injector, an UV-Vis detector, and a fluorescence detector was purchased from Agilent Technologies Inc. (Santa Clara, CA, USA). A digital thermostat water bath was obtained from Changzhou Langyue Co., Ltd. (Changzhou, China). YQ620C ultrasonic cleaning instrument was purchased from Shanghai Yijing Ultrasonic Instruments Co., Ltd. (Shanghai, China). UPC-11-10T ultra pure water system was obtained from Wuhan Ulupure Pure Water Equipment Co., Ltd. (Wuhan, China). 
<smiles>O=c1cc(-c2ccccc2)oc2ccccc12</smiles>

b<smiles>O=c1cc(-c2ccccc2)oc2cc(O)c(O)c(O)c12</smiles>

Baicalein<smiles>O=c1cc(-c2ccc(O)cc2)oc2cc(O)cc(O)c12</smiles>

Apigenin<smiles>O=c1cc(-c2ccc(O)c(O)c2)oc2cc(O)cc(O)c12</smiles>

Luteolin<smiles>O=c1c(-c2ccc(O)cc2)coc2cc(O)cc(O)c12</smiles>

Genistein<smiles>O=c1c(-c2ccc(O)cc2)coc2cc(O)ccc12</smiles>

Daidzein<smiles>O=c1c(-c2ccc(O)cc2)coc2cc(CC3OC(CO)C(O)C(O)C3O)cc(O)c12</smiles>

Genistin<smiles>O=c1c(O)c(-c2ccc(O)cc2)oc2cc(O)cc(O)c12</smiles>

Kaempferol<smiles>O=c1c(O)c(-c2ccc(O)c(O)c2)oc2cc(O)cc(O)c12</smiles>

Quercetin

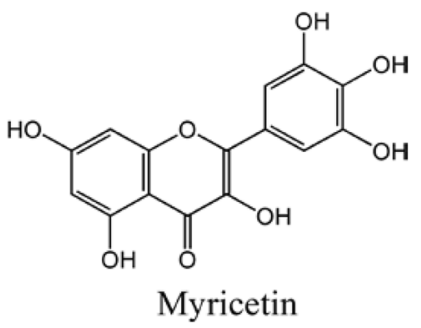

Fig. 1 a Matrix structure of flavonoids, and $\mathbf{b}$ structural formulas of different flavonoids

\section{Liquid-state fermentation of MAL}

MAL spores were prepared according to the method described in our previous study (Huang et al. 2019). The liquid-state fermentation of MAL was performed as follows: first, $1.0 \mathrm{~mL}$ of the spore solution $\left(7.0 \times 10^{6}\right.$ spore/ $\mathrm{mL}$ ) was inoculated into a $250 \mathrm{~mL}$ Erlenmeyer flask with $100 \mathrm{~mL}$ seed culture medium $(\mathrm{m} / \mathrm{v})(3.0 \%$ glucose, $0.2 \%$ $\mathrm{KH}_{2} \mathrm{PO}_{4}, 0.3 \% \mathrm{NaNO}_{3}, 0.05 \% \mathrm{KCl}, 0.05 \% \mathrm{MgSO}_{4} \cdot 7 \mathrm{H}_{2} \mathrm{O}$ ), and shaken at $180 \mathrm{rpm}$ and $30{ }^{\circ} \mathrm{C}$ in a constant temperature incubator for $48 \mathrm{~h}$. Subsequently, $5.0 \mathrm{~mL}$ of MAL seed solution was inoculated onto $100 \mathrm{~mL}$ aseptic liquid-state fermentation medium $(\mathrm{m} / \mathrm{v})(2.0 \%$ rice powder, $0.2 \% \mathrm{NaNO}_{3}, 0.05 \% \mathrm{KH}_{2} \mathrm{PO}_{4}, 0.1 \% \mathrm{~K}_{2} \mathrm{HPO}_{4}$, $0.1 \% \mathrm{MgSO}_{4} \cdot 7 \mathrm{H}_{2} \mathrm{O}$ ), and rice powder inorganic salt medium with $0-5.0 \mathrm{~g} / \mathrm{L}$ of genistein or other flavonoids at $30{ }^{\circ} \mathrm{C}, 180 \mathrm{rpm}$. The culture was incubated in a constant temperature shaking incubator. After completion of MAL fermentation, $1.0 \mathrm{~mL}$ of the fermentation broth was added to $2.0 \mathrm{~mL}$ methanol in a centrifuge tube, mixed well, and placed in a $60^{\circ} \mathrm{C}$ water bath for $1 \mathrm{~h}$, shaking constantly. After the fermentation broth was removed for cooling, the supernatant was taken and centrifuged at $8000 \mathrm{rpm}$ for $15 \mathrm{~min}$ at $25^{\circ} \mathrm{C}$. After filtration through a $0.22 \mu \mathrm{m}$ microporous organic filter for HPLC analysis. 
Effect of genistein and other flavonoids on biomass of MAL Briefly, $5.0 \mathrm{~mL}$ of MAL seed solution was inoculated into a $250 \mathrm{~mL}$ Erlenmeyer flask with $100 \mathrm{~mL}$ of liquidstate fermentation medium supplemented with genistein or other flavonoids, along with a blank group, and fermented for $12 \mathrm{~d}$ at $30^{\circ} \mathrm{C}$ in a constant temperature shaking incubator at $180 \mathrm{rpm}$. Each experimental and blank group was replicated at least three times. Next, the mycelium reached a constant weight and was measured.

\section{Effect of genistein and other flavonoids on pigment production by MAL}

The liquid-state fermentation was carried out according to the above mentioned fermentation process. Genistein and other flavonoids were added to the culture medium and set with a blank control group. The three primary pigments were detected according to our previous study (Huang et al. 2019). Briefly, $1.0 \mathrm{~mL}$ of the fermentation broth was transferred into a $5.0 \mathrm{~mL}$ centrifuge tube. Following which $2.0 \mathrm{~mL}$ of methanol was added and mixed well by shaking. The centrifuge tube containing the sample was then placed in a water bath at $60^{\circ} \mathrm{C}$ for $1 \mathrm{~h}$. After removing the sample from the water bath and cooling, it was filtered with a $0.22 \mu \mathrm{m}$ organic filter. Further, 100 $\mu \mathrm{L}$ was measured on a 96-well microtiter plate using a spectrophotometer. The yellow, orange, and red pigments were detected at $410 \mathrm{~nm}, 470 \mathrm{~nm}$, and $510 \mathrm{~nm}$, respectively. The measured result was multiplied by the dilution factor to obtain the desired pigment value. Additionally, the yellow pigment was determined by HPLC. The HPLC analytical conditions were as follows: a Thermo Syncronis $\mathrm{C}_{18}$ column $(250 \times 4.6 \mathrm{~mm}$ i.d., $5 \mu \mathrm{m})$ was used to determine the yellow pigment at $30{ }^{\circ} \mathrm{C}$, using a UV-vis detector set at $410 \mathrm{~nm}$. Mobile phase was acetonitrile/ $\mathrm{H}_{2} \mathrm{O}(75: 25, \mathrm{v} / \mathrm{v})$, at a flow rate of $1.00 \mathrm{~mL} / \mathrm{min}$ by isocratic elution, and automatic injection was set to $20 \mu \mathrm{L}$.

\section{HPLC and UPLC-QTOF-MS analysis}

HPLC analysis was carried out at $30{ }^{\circ} \mathrm{C}$, using a Thermo Syncronis $\mathrm{C}_{18}$ column $(250 \times 4.6 \mathrm{~mm}$ i.d., $5 \mu \mathrm{m})$ and a fluorescence detector $(\lambda \mathrm{ex}=331 \mathrm{~nm}, \lambda \mathrm{em}=500 \mathrm{~nm})$. The mobile phase was acetonitrile/ $\mathrm{H}_{2} \mathrm{O}(60: 40, \mathrm{v} / \mathrm{v}), \mathrm{pH}$ 2.6 (adjusted with phosphoric acid), at a flow rate of $1.0 \mathrm{~mL} / \mathrm{min}$ by isocratic elution, and automatic injection was set to $20 \mu \mathrm{L}$. The UPLC-QTOF-MS analytical conditions were as follows. The UPLC was carried out on a Waters Acquity UPLC BEH $\mathrm{C}_{18}(100 \times 2.1 \mathrm{~mm}$ i.d., $1.7 \mu \mathrm{m}$, Waters, Milford, USA) at $25{ }^{\circ} \mathrm{C}$ with a flow rate of $0.3 \mathrm{~mL} / \mathrm{min}$ using an Agilent 1290 UPLC system (Agilent, Santa Clara, CA, USA). Mobile phase A contained water with $0.1 \%$ formic acid, and phase $B$ consisted of acetonitrile. The gradient elution started with $10 \% \mathrm{~B}$, linearly increased to $75 \%$ B in $20 \mathrm{~min}$, and later on to $100 \%$
$\mathrm{B}$ in $0.1 \mathrm{~min}$, kept constant for $2.9 \mathrm{~min}$, and returned to $90 \% \mathrm{~A}$ in $0.1 \mathrm{~min}$, followed by $2.9 \mathrm{~min}$ of re-equilibration. Agilent 6538 ESI-QTOF-MS was used, operating in the positive ion mode in the mass range of 60-1700 Da with the following mass spectrometer conditions: fragmentor $=130 \mathrm{~V}$; collision energy $=60 \mathrm{eV}$; nebulizer gas $=40$ psi; capillary voltage $=4500 \mathrm{~V}$; drying gas flow $=10 \mathrm{~L} /$ min; gas temperature $=350{ }^{\circ} \mathrm{C}$.

\section{Statistical analysis}

The statistical analysis was carried out as described previously (Huang et al. 2019). All experiments were performed in triplicate (at least) and values were expressed as means \pm standard deviations.

\section{Results}

Effect of adding genistein on citrinin production of MAL in different content rice powder medium

In this study, rice powder was used as a carbon source for the medium. During fermentation of Monascus, changes in carbon source resulted in important effects on secondary metabolites (Carels and Shepherd 1977; Wong et al. 1981). Optimizing the amount of the carbon source added is necessary for subsequent experiments. As shown in Fig. 2a, the citrinin content decreased as the added amount of rice powder increased. After adding genistein $(2.0 \mathrm{~g} / \mathrm{L})$, citrinin showed a significant decrease trend compared with the blank group. When the amount of rice powder was $5.0 \mathrm{~g} / \mathrm{L}$ and $10.0 \mathrm{~g} / \mathrm{L}$, the reduction rate of citrinin was about $22 \%$. When the amount of rice powder increased to $20.0 \mathrm{~g} / \mathrm{L}$, the decrease of citrinin was more obvious, with a rate of about $80 \%$; the reduction rates exceeded $88 \%$ when rice powder was added at $30.0 \mathrm{~g} / \mathrm{L}$. It was observed that the dry weight cells (biomass) increased as the amount of supplemented rice powder increased (Fig. 2a), suggesting that the addition of geinstein did not inhibit the growth of MAL (Fig. 2a).

It could be seen from the change of the pigments in Fig. $2 \mathrm{~b}$ that the production of yellow pigment was highest for MAL, and the orange and red pigments were lower. As the amount of rice powder added increased, the yield of the three pigments gradually decreased. Among them, the content of the three pigments was similar when the amount of rice powder was $5.0 \mathrm{~g} / \mathrm{L}$ and $10.0 \mathrm{~g} / \mathrm{L}$, and notable pigmentation was observed after adding genistein. When $20.0 \mathrm{~g} / \mathrm{L}$ rice powder was added, the content of yellow pigment remained the same; however, the orange and red pigments decreased. The addition of genistein still promoted the production of Monascus pigment. When the amount of $30.0 \mathrm{~g} / \mathrm{L}$ rice powder was added, the content of the three pigments was significantly reduced. Therefore, we found that when the amount of rice powder was increased, the pigment content was 

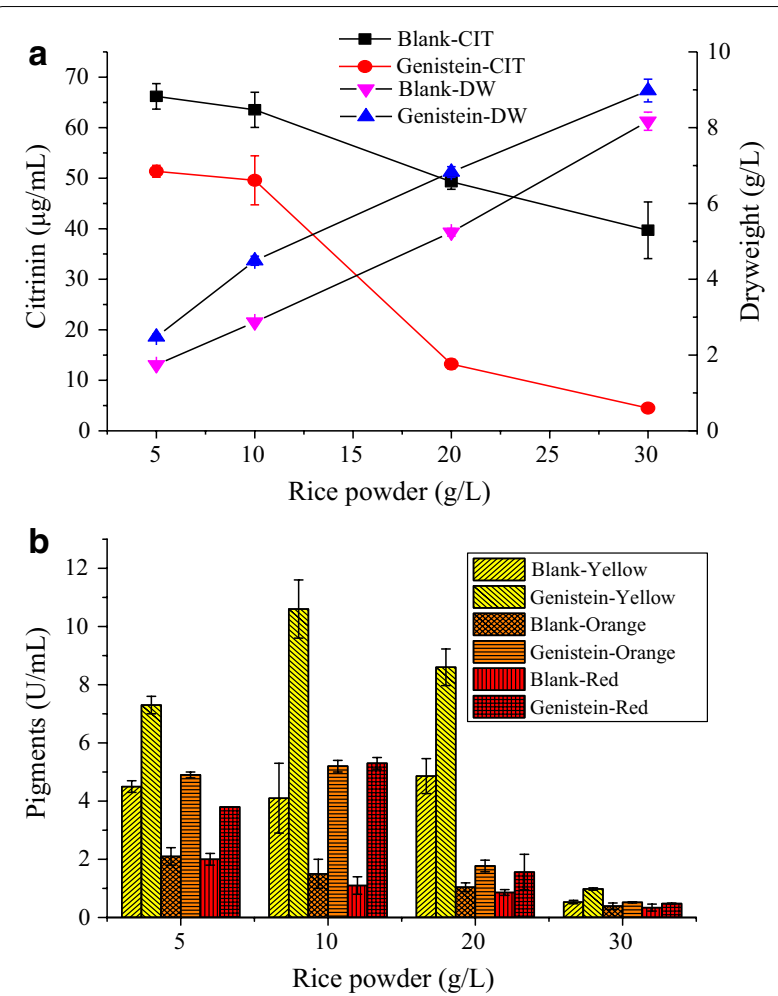

Fig. 2 Effects of genistein ( $2.0 \mathrm{~g} / \mathrm{L})$ on a citrinin (CIT), biomass, and b pigments production by MAL in different content of rice powder in liquid-state fermentation medium at $30^{\circ} \mathrm{C}, 180 \mathrm{rpm}$ for 12 days. Significant differences of different the dots and the columns at $p<0.05$

lowered. Combined with the addition of genistein, the citrinin had a better reduction effect and could improve the pigment yield.

\section{Growth curve of Monascus in rice powder medium}

As shown in Fig. 3a, a growth curve of citrinin produced by MAL fermented in rice powder inorganic salt medium. The yield of citrinin increased first, and it gradually became stable after reaching its highest point. The yield of citrinin was greatest at 12 days of fermentation. After the addition of $2.0 \mathrm{~g} / \mathrm{L}$ genistein, the yield of citrinin was significantly reduced, which stabilized after reaching the highest value in 10 days. The reduction rate after genistein addition was the lowest at 12 days, approximately $80 \%$. The growth trend of the dry weight of the bacteria was consistent with the blank group and genistein addition. Further, after genistein addition, it did not affect the growth stages of the cells, which could be seen from MAL staining in Fig. 3b. During the growth of MAL, the content of yellow pigment was significantly higher than orange and red pigments. When genistein was added, the three pigment contents were higher than those in the blank group. It could be seen that genistein
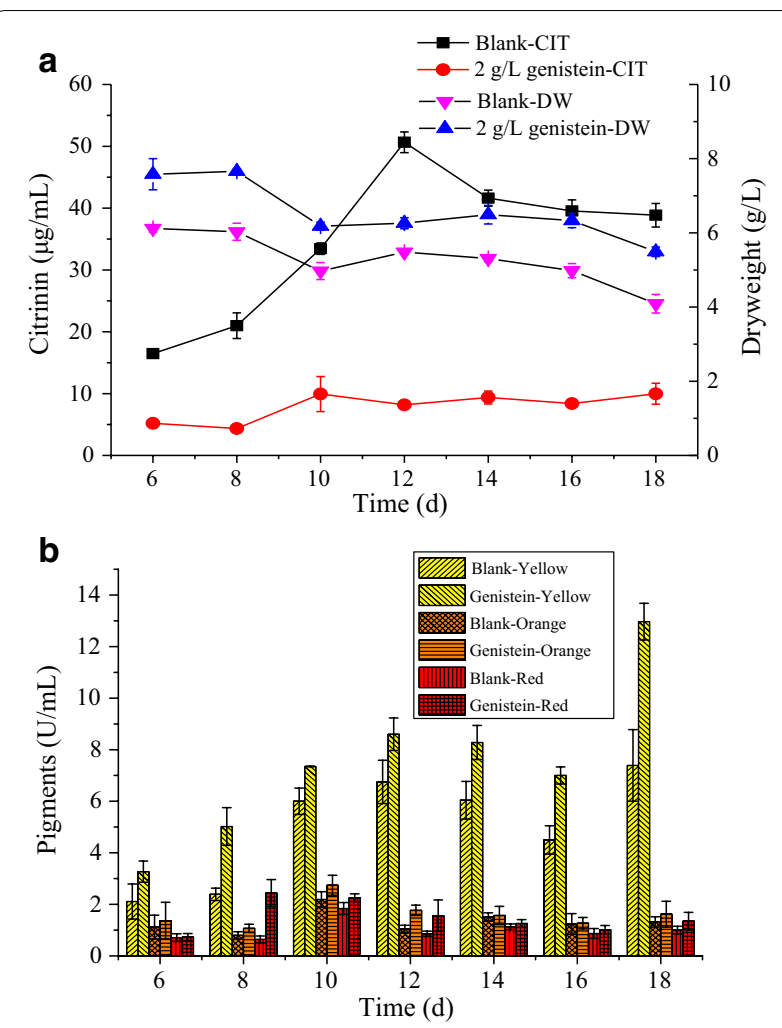

Fig. 3 Effects of genistein ( $2.0 \mathrm{~g} / \mathrm{L}$ ) on a citrinin (CIT), biomass, and b pigments production by MAL at $30^{\circ} \mathrm{C}, 180 \mathrm{rpm}$ during different liquid-state fermentation time. Significant differences of different the dots and the columns at $p<0.05$

had a significant effect on citrinin and promoted pigment growth.

\section{UPLC-QTOF-MS analysis of fermentation samples of different additions of flavonoids}

The fermentation samples of different addition of flavonoids in the medium were analyzed by UPLC-QTOFMS. The main compounds, including citrinin $\left(\mathrm{ESI}^{+}\right.$ 251.0893), monascin $\left(\mathrm{ESI}^{+}\right.$359.1836), ankaflavin $\left(\mathrm{ESI}^{+}\right.$ 387.2151), and five unknown compounds (EIS ${ }^{+} 385.1995$, $374.2720,318.2980,432.2351$, and 302.3042), were found in the total ion chromatogram, and their retention times were $9.22 \mathrm{~min}, 16.24 \mathrm{~min}, 18.68 \mathrm{~min}, 3.57 \mathrm{~min}$, $11.56 \mathrm{~min}, 11.75 \mathrm{~min}, 13.40 \mathrm{~min}$, and $13.90 \mathrm{~min}$, respectively (Fig. S1 and Fig. S2, Additional file 1). The results also showed that the different flavonoids had different effects on citrinin reduction in the fermentation samples, and genistein and baicalein markedly affected citrinin production. In addition, there were no new compounds generated in fermentation samples following flavonoid addition (Additional file 1: Fig. S1). The compounds retention time was $11.04 \mathrm{~min}\left(\mathrm{ESI}^{+} 283.0648\right)$ and $10.36 \mathrm{~min}\left(\mathrm{ESI}^{+} 359.1829\right)$ after adding baicalein and 
myricetin (Additional file 1: Fig. S1), respectively, and the two compounds were derived from raw materials.

\section{Structure-activity relationship analysis}

As shown in Fig. 4a, the effect of different amounts of flavonoids on citrinin reduction after liquid-state fermentation of MAL demonstrated different effects on citrinin. Overall, after reaching $2.0 \mathrm{~g} / \mathrm{L}$, the reduction in citrinin was relatively flat to constant. This might be related to the water solubility of flavonoids. Most of the flavonoids are poorly soluble in water; therefore, these are not fully utilized in the fermentation broth. Accordingly,
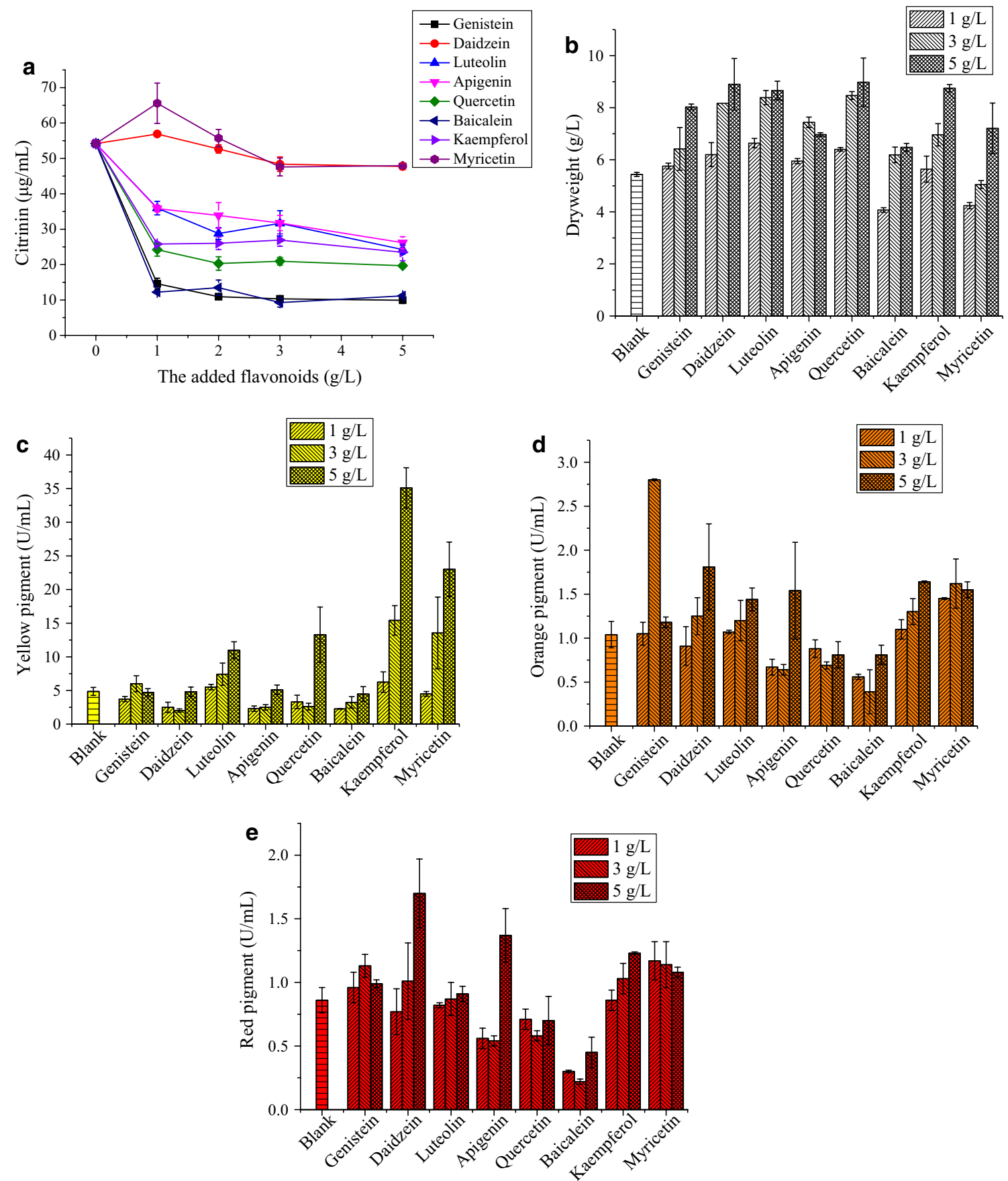

Fig. 4 Effects of different types and quantities of flavonoids (1.0-5.0 g/L) on a citrinin, b biomass, c yellow pigment, $\mathbf{d}$ orange pigment, and e red pigment production by MAL in liquid-state fermentation at $30^{\circ} \mathrm{C}, 180 \mathrm{rpm}$ for 12 days. Significant differences of different the columns at $\mathrm{p}<0.05$ 
$2.0 \mathrm{~g} / \mathrm{L}$ was used in the experiment. Nine flavonoids had different abilities to reduce citrinin. Among them, daidzein and myricetin had the weakest effect. When the addition amount was $1.0 \mathrm{~g} / \mathrm{L}$ and $2.0 \mathrm{~g} / \mathrm{L}$, daidzein or myricetin had no inhibitory effect on citrinin production by MAL. When the dosage was $3.0 \mathrm{~g} / \mathrm{L}$ and $5.0 \mathrm{~g} / \mathrm{L}$, citrinin was reduced by about $10 \%$. The reducing effects of genistein and baicalein on citrinin were similar. When $2.0 \mathrm{~g} / \mathrm{L}$ genistein or baicalein was added, citrinin was reduced by about $80 \%$; however, when baicalein was added, MAL barely produced pigments (Additional file 1: Fig. S3). When $2.0 \mathrm{~g} / \mathrm{L}$ genistein was added, citrinin was reduced by about $60 \%$. Because genistein is relatively expensive, the content optimization experiment was not performed. When $2.0 \mathrm{~g} / \mathrm{L}$ of apigenin, luteolin, kaempferol, and quercetin were added to the medium, the content of citrinin was reduced by $46.9 \%, 45 \%, 51.1 \%$, and $66.7 \%$, respectively. When the dosage of these flavonoids was $3.0 \mathrm{~g} / \mathrm{L}$ and $5.0 \mathrm{~g} / \mathrm{L}$, the effect on citrinin reduction was similar to $2.0 \mathrm{~g} / \mathrm{L}$ flavonoid addition. The change of MAL biomass can be seen in Fig. 4b. Overall, the biomass increased with increase in flavonoid content, and only baicalein and myricetin had lower biomasses. The amount of biomass reflects the growth of MAL. Adding baicalein and myricetin might inhibit MAL growth, while the other six flavonoids did not affect growth. Figure $4 \mathrm{c}-\mathrm{e}$ showed the variation of the contents of Monascus yellow, orange, and red pigments. Overall, with the increase in flavonoids, the pigment contents increased. For yellow, orange, and red pigments, the yield of baicalein was lower than the blank group. It is concluded that baicalein did not promote pigment production while reducing citrinin. Genistein had a higher ability to produce pigments than other flavonoids (Table 1). Therefore, the effect of genistein on the MAL fermentation was the best.

\section{Discussion}

In this study, different rice powder contents exerted specific effects on citrinin production. When adding genistein and the same amount of rice powder, citrinin could be reduced evenly. Adding $2.0 \mathrm{~g} / \mathrm{L}$ genistein to the culture medium had the best effect on citrinin reduction, and the content of pigments was also increased. However, the pigment content was the highest under the conditions of low rice powder content. This is possibly because the growth cycle of MAL was shortened due to low rice powder content, which makes the fungus produce more secondary metabolites. Citrinin and pigment yields were very high at low rice powder content of the medium. It has been previously found that the increase in rice powder content reduces dissolved oxygen (Hajjaj et al. 1999; Yang et al. 2015) in shaking flasks, slowing the growth
Table 1 The content of two yellow pigments (monascin and ankaflavin) in liquid fermentation samples after adding different flavonoids, as detected by HPLC $(n=6)$

\begin{tabular}{lll}
\hline Experimental group & Monascin $(\boldsymbol{\mu g} / \mathbf{m L})$ & Ankaflavin $(\boldsymbol{\mu g} / \mathbf{m L})$ \\
\hline Blank & $20.69 \pm 1.69$ & $7.25 \pm 0.74$ \\
Genistein & $28.37 \pm 2.72$ & $8.50 \pm 0.36$ \\
Daidzein & $18.99 \pm 2.62$ & $5.53 \pm 0.61$ \\
Luteolin & $22.52 \pm 2.28$ & $6.71 \pm 1.30$ \\
Apigenin & $12.15 \pm 2.76$ & $6.71 \pm 1.33$ \\
Quercetin & $26.89 \pm 1.17$ & $7.79 \pm 0.35$ \\
Baicalein & - & - \\
Kaempferol & $18.97 \pm 2.63$ & $6.10 \pm 1.26$ \\
Myricetin & $32.06 \pm 5.37$ & $8.94 \pm 0.08$ \\
Genistin & $11.36 \pm 5.17$ & $3.52 \pm 2.08$ \\
\hline
\end{tabular}

"-" means no detection

of mycelium and reducing the production of secondary metabolites of MAL. After adding genistein, the growth curve of MAL was also affected. After 12 days of fermentation, citrinin was markedly reduced. After exploring the effects of genistein on metabolites of MAL, we further studied the effects of different kinds of flavonoids with different contents on metabolites of MAL. The structures of these flavonoids are shown in Fig. 1b, which were expressed as flavones, isoflavones, and flavonols.

From Fig. 4, it can be observed that the effects of flavonoids on the metabolites of MAL were different. Different flavonoids exerted different effects on citrinin and pigment. However, it can be seen that the greatest effect of the flavonoids on citrinin reduction at the addition amount of $2.0 \mathrm{~g} / \mathrm{L}$ almost did not affect cell growth. Therefore, we used the addition of $2.0 \mathrm{~g} / \mathrm{L}$ flavonoids for these studies.

Among the nine flavonoids, daidzein and myricetin showed the weakest effect on citrinin; however, genistein and baicalein had the best effect. These nine flavonoids are similar substances; therefore, comparing their structural differences could help us to further understand the relationship between flavonoids and the structure-activity effect on citrinin production by MAL. According to the structural formula, genistein and daidzein differ only at the $\mathrm{C} 5-\mathrm{OH}$ position (Fig. 1); however, the effect of genistein and daidzein on citrinin was quite different. Genistein significantly reduced citrinin content of MAL, but daidzein did not. We speculated that the $\mathrm{C} 5-\mathrm{OH}$ of ring $\mathrm{A}$ is the key site for citrinin reduction. Fischer et al. (2012) studied the effects of genistein and daidzein on the immunity of Caenorhabditis elegans. It was concluded that genistein decreased vitellogenin expression, but daidzein increased vitellogenin expression, which 
showed different trends, which may be related to $\mathrm{C} 5-\mathrm{OH}$. This result was consistent with that of the current study. Poulsen et al. (2009) had reported the effects of genistein and daidzein on a series of physiological indicators in ovariectomized rats. Their results showed that Ileal and fecal digestibility of genistein was significantly greater than that of daidzein. The authors suggested that the difference in metabolism and structure may be responsible for their differences, and further verified that 4-ethylphenol was the main metabolite of genistein in rats. Djiogue et al. (2009) reported that genistein containing $\mathrm{C} 5-\mathrm{OH}$ had stronger binding ability to the estrogen receptor than daidzein, which further proved that $\mathrm{C} 5-\mathrm{OH}$ was an active site of flavonoids. Fang et al. (2019) found that C3-OH, $\mathrm{C} 5-\mathrm{OH}, \mathrm{C}^{\prime}-\mathrm{OCH}_{3}$, and $\mathrm{C4}^{\prime}-\mathrm{OCH}_{3}$ had good activity for the binding of flavonoids to P-Glycoprotein. Liu et al. (2012) studied the inhibitory effect of polymethoxyflavones (PFM) on Aspergillus Niger in citrus. The structure-activity analysis showed that flavones containing the $\mathrm{C} 5-\mathrm{OH}$ group had the strongest antifungal activity, which proved that $\mathrm{C} 5-\mathrm{OH}$ was the active group of flavonoids. Interestingly, in our study, genistein could reduce citrinin content in liquid-state fermentation of MAL, while daidzein had little effect on citrinin (Fig. 4a). Additionally, genistein had no effect on the biomass of MAL (i.e., it did not inhibit the growth of MAL) and could increase pigment production (Fig. 4b). It further indicated that genistein $\mathrm{C} 5-\mathrm{OH}$ played a key role on citrinin reduction during liquid-state fermentation of MAL.

Apigenin is an isomer of genistein, mainly in different substitution positions of the $\mathrm{C}$ ring. The results showed that apigenin reduced citrinin by about $50 \%$, and genistein reduced citrinin by about $80 \%$. From this, we could infer that the benzene ring at the $\mathrm{C} 3$ position can reduce citrinin production more effectively. This should be a secondary site of citrinin reduction, and the B-ring $\mathrm{C}^{\prime}-\mathrm{OH}$ may also be an active site. Larrosa et al. (2006) mentioned that the interaction between $\mathrm{C} 5-\mathrm{OH}$ and $\mathrm{C4}^{\prime}-\mathrm{OH}$ at $\mathrm{C} 3$ facilitates genistein binding to phytoestrogen receptors with greater affinity than daidzein. Zhang et al. (2018) pointed out that hydrophobic groups and hydrogen bonds were important factors to stabilize the binding ability of flavonoids. For estrogenic flavonoids, methylation of hydroxyl group can reduce estrogenic activity; therefore, it is presumed that the hydroxyl group is necessary for flavonoids to possess estrogen. Similarly, the presence of these hydroxyl groups also had an important effect on citrinin reduction.

The structure difference of apigenin and luteolin lies in the hydroxyl number of the B ring. The results showed that apigenin and luteolin reduced citrinin by approximately $50-60 \%$. It was concluded that the number of hydroxyl groups attached to benzene on the B ring did not affect the citrinin content. Kaempferol, quercetin, and myricetin also have structural similarities. They are all flavonols, containing $\mathrm{C} 3-\mathrm{OH}$. On the $\mathrm{B}$ ring, the three hydroxyl groups are connected to 1, 2, and 3 hydroxyl groups, respectively. The citrinin reduction rate of quercetin was about $67 \%$, and that of kaempferol was about $50 \%$. Myricetin had no effect on citrinin. Because the myricetin solution was acidic and its $\mathrm{pH}$ was low during fermentation, it might promote citrinin (Lee et al. 2007). Therefore, we speculated that the ortho-hydroxyl group had a better effect on citrinin reduction for flavonols. For baicalein, there is a hydroxyl group at the C6 position, and the difference of its structure might influence the metabolites of MAL. The results showed that baicalein significantly reduced citrinin production, which was similar to genistein, but the pigments were greatly reduced. During the fermentation process, we also found that the morphology of MAL changed in the medium supplemented with baicalein. Therefore, we speculated that the addition of baicalein might completely change the metabolic pathway of MAL. This requires further exploration in future studies. In addition, studies have shown that $\mathrm{C} 7-\mathrm{OH}$ is also an active site of flavonoids (Echeverry et al. 2010). Comparison with adding genistein and genistin to the medium, the results showed that genistein with $\mathrm{C} 7-\mathrm{OH}$ had better effect on citrinin reduction.

In the study of nine flavonoids, genistein strongly inhibited citrinin production and improved pigment contents. Therefore, $\mathrm{C} 5-\mathrm{OH}$ and $\mathrm{C} 4^{\prime}-\mathrm{OH}$ markedly inhibited citrinin production by MAL. C5-OH played a dominant role in reducing citrinin. Benzene $\mathrm{C}^{\prime}-\mathrm{OH}$ on the $\mathrm{C} 3$ ring also played a role in inhibiting citrinin production; thus, there might be some interaction between them. Wu et al. (2013) also reported that flavonoids exhibited good antimicrobial activity against $\mathrm{E}$. coli, including $\mathrm{C} 5-\mathrm{OH}$ and $\mathrm{C4}^{\prime}-\mathrm{OH}$ in ring $\mathrm{A}$ and $\mathrm{B}$. Xiao et al. (2011a, b) proposed that the hydroxylation of flavonoids had an important effect on the covalent binding of human blood and inhibition of xanthine oxidase activity in bovine blood. Simons et al. (2005) suggested that the degradation of flavonoids by human microorganisms was also related to their structure. The $\mathrm{C}^{\prime}-\mathrm{OH}$ was very important for rapid microbial degradation, but only existed in the presence of $\mathrm{C} 5-\mathrm{OH}$. The presence of methoxy groups in A or $\mathrm{B}$ rings makes flavonoids degradable against microorganisms. Flavonoids with C5-, C7-, and C4'-hydroxyl groups degraded faster than flavonoids lacking all these hydroxyl groups in all three species. Therefore, hydroxylation of specific sites of flavonoids was necessary for their biological activity expression, and it could well explain that flavonoids could reduce citrinin production by liquid-state fermentation of MAL. 
To the best of our knowledge, this is the first study investigating the, structure-activity relationship of flavonoids on citrinin reduction by Monascus during liquidstate fermentation. Genistein and other flavonoids could affect the citrinin and pigments production by MAL. The $\mathrm{C} 5-\mathrm{OH}, \mathrm{C}^{\prime}-\mathrm{OH}$, and $\mathrm{C} 7-\mathrm{OH}$ of flavonoids might play a key role for their effects on citrinin reduction in liquidstate fermentation of MAL. The mechanism of flavonoids on metabolites of Monascus calls for further study of its intrinsic genomics, proteomics, and metabonomics.

\section{Supplementary information}

Supplementary information accompanies this paper at https://doi. org/10.1186/s13568-020-0962-7.

Additional file 1. Fig.S1. Total ion chromatogram of UPLC-QTOF-MS of the liquid fermentation samples following addition of different flavonoids and blank group. 2-citrinin, 7- monascin, 8- ankaflavin. Fig. S2 QTOF-MS of several main compounds in the liquid fermentation samples following addition of different flavonoids. Fig. S3 The liquid fermentation samples following addition of different flavonoids and blank group.

\section{Authors' contributions}

YLW and HG carried out most of the experiments except UPLC-QTOF-MS related part and analyzed the relative data; JHX carried out the UPLC-QTOF-MS experiments and reviewed the manuscript; $X J L$ assisted to carry out experiments. ZBH participated in the data analysis and wrote the manuscript. All authors read and approved the final manuscript.

\section{Funding}

This work was financially supported by the National Natural Science Foundation of China (No. 31671837), and supported the Training Plan for the Main Subject of Academic Leaders of Jiangxi Province (No. 20172BCB22006), and also supported the Research Project of State Key Laboratory of Food Science and Technology (No.SKLF-ZZB-201924).

\section{Availability of data and materials}

We conducted experiments and data generated. All data is shown in figures, tables and additional data.

\section{Ethics approval and consent to participate}

This article does not contain any studies with human participants or animals performed by any of the authors.

\section{Consent for publication}

Not applicable.

\section{Competing interests}

The authors declare that they have no competing interests.

\section{Author details}

${ }^{1}$ State Key Laboratory of Food Science and Technology, Nanchang University, No. 235 Nanjing East Road, Nanchang 330047, China. ${ }^{2}$ Sino-German Joint Research Institute, Nanchang University, No. 235 Nanjing East Road, Nanchang 330047, China. ${ }^{3}$ The First Affiliated Hospital of Nanchang University, Nanchang University, No. 17 Yongwai Main Street, Nanjing West Road, Nanchang 330006, China.

Received: 11 January 2020 Accepted: 21 January 2020

Published online: 03 February 2020

\section{References}

Akilandeswari P, Pradeep BV (2016) Exploration of industrially important pigments from soil fungi. Appl Microbiol Biotechnol 100:1631-1643. https:// doi.org/10.1007/s00253-015-7231-8

Balakrishnan B, Karki S, Chiu SH, Kim HJ, Suh JW, Nam B, Yoon YM, Chen CC, Kwon HJ (2013) Genetic localization and in vivo characterization of a Monascus azaphilone pigment biosynthetic gene cluster. Appl Microbiol Biotechnol 97:6337-6345. https://doi.org/10.1007/s00253-013-4745-9

Benavente-García O, Castillo J (2008) Update on uses and properties of citrus flavonoids: new findings in anticancer, cardiovascular, and antiinflammatory activity. J Agric Food Chem 56(15):6185-6205. https://doi. org/10.1021/jf8006568

Carels M, Shepherd D (1977) The effect of different nitrogen sources on pigment production and sporulation of Monascus species in submerged, shaken culture. Can J Microbiol 23(10):1360-1372. https://doi. org/10.1139/m77-205

Chen W, He Y, Zhou Y, Shao Y, Feng Y, Li M, Chen F (2015) Edible filamentous fungi from the species Monascus: early traditional fermentations, modern molecular biology, and future genomics. Compr Rev Food Sci F 14(5):555-567. https://doi.org/10.1111/1541-4337.12145

Chen W, Chen R, Liu Q, He Y, He K, Ding X, Kang L, Guo X, Xie N, Zhou Y, Lu Y, Cox RL, Molnar I, Li M, Shao Y, Chen F (2017) Orange, red, yellow: biosynthesis of azaphilone pigments in Monascus fungi. Chem Sci 8(7):49174925. https://doi.org/10.1039/c7sc00475

Cheng TC, Lu JF, Wang JS, Lin L, Kuo HI, Chen BH (2011) Antiprolifer-ation effect and apoptosis mechanism of prostate cancer cell PC-3 by flavonoids and saponins prepared from Gynostemma pentaphyllum. J Agric Food Chem 59(20):11319-11329. https://doi.org/10.1021/jf2018758

Dikshit R, Tallapragada P (2018) Development and screening of mutants from Monascus sanguineus for secondary metabolites production. Beni-Suef Univ J Basic Appl Sci 7(2):235-240. https://doi.org/10.1016/j.bjbas .2018.03.001

Djiogue S, Halabalaki M, Alexi X, Njamen D, Fomum ZT, Alexis MN, Skaltsounis AL (2009) Isoflavonoids from Erythrina poeppigiana: evaluation of their binding affinity for the estrogen receptor. J Nat Prod 72(9):1603-1607. https://doi.org/10.1021/np900271m

Dufosse $L$ (2018) Red colourants from filamentous fungi: are they ready for the food industry? J Food Compos Anal 69:156-161. https://doi. org/10.1016/j.jfca.2017.11.002

Echeverry C, Arredondo F, Abin-Carriquiry JA, Midiwo JO, Ochieng C, Kerubo L, Dajas F (2010) Pretreatment with natural flavones and neuronal cell survival after oxidative stress: a structure-activity relationship study. J Agric Food Chem 58(4):2111-2115. https://doi.org/10.1021/jf902951v

Fan M, Ding H, Zhang G, Hu X, Gong D (2019) Relationships of dietary flavonoid structure with its tyrosinase inhibitory activity and affinity. LWT-Food Sci Technol 107:25-34. https://doi.org/10.1016/j.lwt.2019.02.076

Fang Y, Lu Y, Zang X, Wu T, Qi X, Pan S, Xu X (2016) 3D-QSAR and docking studies of flavonoids as potent Escherichia coli inhibitors. Sci Rep 6:23634. https://doi.org/10.1038/srep23634

Fang Y, Xia M, Liang F, Cao W, Pan S, Xu X (2019) Establishment and use of human mouth epidermal carcinoma (KB) cells overexpressing P-glycoprotein to characterize structure requirements for flavonoids transported by the efflux transporter. J Agric Food Chem 67(8):2350-2360. https://doi. org/10.1021/acs.jafc.9b00039

Fischer M, Regitz C, Kahl M, Werthebach M, Boll M, Wenzel U (2012) Phytoestrogens genistein and daidzein affect immunity in the nematode Caenorhabditis elegans via alterations of vitellogenin expression. Mol Nutr Food Res 56(6):957-965. https://doi.org/10.1021/acs.jafc.9b00039

Gayathri L, Dhivya R, Dhanasekaran D, Periasamy VS, Alshatwi AA, Akbarsha MA (2015) Hepatotoxic effect of ochratoxin A and citrinin, alone and in combination, and protective effect of vitamin E: in vitro study in HepG2 cell. Food Chem Toxicol 83:151-163. https://doi.org/10.1016/j.fct.2015.06.009

Gomes DC, Takahashi JA (2016) Sequential fungal fermentation-biotransformation process to produce a red pigment from sclerotiorin. Food Chem 210:355-361. https://doi.org/10.1016/j.foodchem.2016.04.057

Hajjaj H, Blanc PJ, Groussac E, Goma G, Uribelarrea JL, Loubiere P (1999) Improvement of red pigment/citrinin production ratio as a function of environmental conditions by Monascus ruber. Biotechnol Bioeng 64(4):497-501

Hilares RT, de Souza RA, Marcelino PF, da Silva SS, Dragone G, Mussatto SI, Santos JC (2018) Sugarcane bagasse hydrolysate as a potential feedstock 
for red pigment production by Monascus ruber. Food Chem 245:786-791. https://doi.org/10.1016/j.foodchem.2017.11.111

Hu Y, Zhou Y, Mao Z, Li H, Chen F, Shao Y (2016) NAD+-dependent HDAC inhibitor stimulates Monascus pigment production but inhibit citrinin. AMB Express 7:166. https://doi.org/10.1186/s13568-017-0467-1

Huang Z, Zhang L, Wang Y, Gao H, Li X, Huang X, Huang T (2019) Effects of rutin and its derivatives on citrinin production by Monascus aurantiacus Li AS3.4384 in liquid fermentation using different types of media. Food Chem 284:205-212. https://doi.org/10.1016/j.foodchem.2019.01.109

Jia XQ, Xu ZN, Zhou LP, Sung CK (2010) Elimination of the mycotoxin citrinin production in the industrial important strain Monascus purpureus SM001. Metab Eng 12(1):1-7. https://doi.org/10.1016/j.ymben.2009.08.003

Kang B, Zhang X, Wu Z, Wang Z, Park S (2014) Production of citrinin-free Monascus pigments by submerged culture at low pH. Enzyme Microb Technol 55:50-57. https://doi.org/10.1016/j.enzmictec.2013.12.007

Kundu P, Patel S, Meling DD, Deal K, Gao L, Helferich WG, Flaws JA (2018) The effects of dietary levels of genistein on ovarian follicle number and gene expression. Reprod Toxicol 81:132-139. https://doi.org/10.1016/j.repro tox.2018.07.085

Larrosa M, González-Sarrías A, García-Conesa MT, Tomás-Barberán FA, Espín JC (2006) Urolithins, ellagic acid-derived metabolites produced by human colonic microflora, exhibit estrogenic and antiestrogenic activities. J Agric Food Chem 54(5):1611-1620. https://doi.org/10.1021/jf0527403

Lee CL, Hung HK, Wang JJ, Pan TM (2007) Improving the ratio of monacolin K to citrinin production of Monascus purpureus NTU 568 under dioscorea medium through the mediation of $\mathrm{pH}$ value and ethanol addition. J Agric Food Chem 55(16):6493-6502. https://doi.org/10.1021/jf0711946

Li N, Liu JH, Zhang J, Yu BY (2008) Comparative evaluation of cytotoxicity and antioxidative activity of 20 flavonoids. J Agric Food Chem 56(10):38763883. https://doi.org/10.1021/jf073520n

Li L, Chen S, Gao M, Ding B, Zhang J, Zhou Y, Liu Y, Yang H, Wu Q, Chen F (2019) Acidic conditions induce the accumulation of orange Monascus pigments during liquid-state fermentation of Monascus ruber M7. Appl Microbiol Biotechnol (in press). https://doi.org/10.1007/s00253-01910114-8

Liao C, Chen Y, Lin H, Chiueh L, Shih Y (2014) Incidence of citrinin in red yeast rice and various commercial Monascus products in Taiwan from 2009 to 2012. Food Control 38:178-183. https://doi.org/10.1016/j.foodc ont.2013.10.016

Liu L, Xu X, Cheng D, Yao X, Pan S (2012) Structure-activity relationship of citrus polymethoxylated flavones and their inhibitory effects on Aspergillus niger. J Agric Food Chem 60(17):4336-4341. https://doi.org/10.1021/jf301 2163

Lu F, Liu L, Huang Y, Zhang X, Wang Z (2018) Production of Monascus pigments as extracellular crystals by cell suspension culture. Appl Microbiol Biotechnol 102:677-687. https://doi.org/10.1007/s00253-017-8646-1

Lv J, Qian GF, Chen L, Liu H, Xu HX, Xu GR, Zhang BB, Zhang C (2018) Efficient biosynthesis of natural yellow pigments by Monascus purpureus in a novel integrated fermentation system. J Agric Food Chem 66(4):918-925. https://doi.org/10.1021/acs.jafc.7b05783

Nigović B, Sertić M, Mornar A (2013) Simultaneous determination of lovastatin and citrinin in red yeast rice supplements by micellar electrokinetic capillary chromatography. Food Chem 138(1):531-538. https://doi. org/10.1016/j.foodchem.2012.10.104

Olagaray KE, Bradford BJ (2019) Plant flavonoids to improve productivity of ruminants-a review. Anim Feed Sci Tech 251:21-36. https://doi. org/10.1016/j.anifeedsci.2019.02.004

Orak T, Caglar O, Ortucu S, Ozkan H, Taskin M (2018) Chicken feather peptone: a new alternative nitrogen source for pigment production by Monascus purpureus. J Biotechnol 271:56-62. https://doi.org/10.1016/j.jbiot ec.2018.02.010

Poulsen RC, du Loots T, Moughan PJ, Kruger MC (2009) Ileal and faecal digestibility of daidzein and genistein and plasma bioavailability of these isoflavones and their bioactive metabolites in the ovariectomised rat. Mol Nutr Food Res 53(S1):27-35. https://doi.org/10.1002/mnfr.200800080

Rumora L, Domijan AM, Zanić Grubišić T, Segvić Klarić M (2014) Differential activation of MAPKs by individual and combined ochratoxin A and citrinin treatments in porcine kidney PK15 cells. Toxicon 90:174-183. https:// doi.org/10.1016/j.toxicon.2014.08.006
Schweiggert RM (2018) Perspective on the ongoing replacement of artificial and animal-based dyes with alternative natural pigments in foods and beverages. J Agric Food Chem 66:3074-3081. https://doi.org/10.1021/ acs.jafc.7b05930

Shimizu T, Kinoshita H, Nihira T (2007) Identification and in vivo functional analysis by gene disruption of ctnA, an activator gene involved in citrinin biosynthesis in Monascus purpureus. Appl Environ Microbiol 73(16):50975103. https://doi.org/10.1128/AEM.01979-06

Simons AL, Renouf M, Hendrich S, Murphy PA (2005) Human gut microbial degradation of flavonoids: structure-function relationships. J Agric Food Chem 53(10):4258-4263. https://doi.org/10.1021/jf0500177

Tsukahara M, Shinzato N, Tamaki Y, Namihira T, Matsui T (2009) Red yeast rice fermentation by selected Monascus sp. with deep-red color, lovastatin production but no citrinin, and effect of temperature-shift cultivation on lovastatin production. Appl Biochem Biotechnol 158(2):476-482. https:// doi.org/10.1007/s12010-009-8553-8

Wan Y, Zhang J, Han H, Li L, Liu Y, Gao M (2017) Citrinin-producing capacity of Monascus purpureus in response to low-frequency magnetic fields. Process Biochem 53:25-29. https://doi.org/10.1016/j.procbio.2016.11.009

Wang L, Yan F, Zhao X, Li Y (2019) Effects of nitro- and amino-group on the antioxidant activity of genistein: a theoretical study. Food Chem 275:339-345. https://doi.org/10.1016/j.foodchem.2018.09.108

Wolfe KL, Liu RH (2008) Structure-activity relationships of flavonoids in the cellular antioxidant activity assay. J Agric Food Chem 56(18):8404-8411. https://doi.org/10.1021/jf8013074

Wong HC, Lin YC, Koehler PE (1981) Regulation of growth and pigmentation of Monascus purpureus by carbon and nitrogen concentrations. Mycologia 73(4):649-654. https://doi.org/10.1080/00275514.1981.12021392

Wu T, Zang X, He M, Pan S, Xu X (2013) Structure-activity relationship of flavonoids on their anti-Escherichia coli activity and inhibition of DNA gyrase. J Agric Food Chem 61(34):8185-8190. https://doi.org/10.1021/jf402222v

Xiao JB, Huo JL, Yang F, Chen XQ (2011a) Noncovalent interaction of dietary polyphenols with bovine hemoglobin in vitro: molecular structure/property-affinity relationship aspects. J Agric Food Chem 59(15):8484-8490. https://doi.org/10.1021/jf201536v

Xiao J, Zhao Y, Wang H, Yuan Y, Yang F, Zhang C, Yamamoto K (201 1b) Noncovalent interaction of dietary polyphenols with common human plasma proteins. J Agric Food Chem 59(19):10747-10754. https://doi. org/10.1021/jf2029829

Xu D, Xu Y, Liu G, Hou Z, Yuan Y, Wang S, Cao Y, Sun B (2018) Effect of carrier agents on the physical properties and morphology of spray-dried Monascus pigment powder. LWT-Food Sci Technol 98:299-305. https:// doi.org/10.1016/j.lwt.2018.08.056

Yang J, Chen Q, Wang W, Hu J, Hu C (2015) Effect of oxygen supply on Monascus pigments and citrinin production in submerged fermentation. J Biosci Bioeng 119(5):564-569. https://doi.org/10.1016/j.jbiosc.2014.10.014

Yongsmith B, Thongpradis P, Klinsupa W, Chantrapornchai W, Haruthaithanasan W (2013) Fermentation and quality of yellow pigments from golden brown rice solid culture by a selected Monascus mutant. Appl Microbiol Biotechnol 97:8895-8902. https://doi.org/10.1007/s00253-013-5106-4

Zhang T, Zhong S, Meng Y, Deng W, Hou L, Wang Y, Xing X, Guan T, Zhang J, Li T (2018) Quantitative structure-activity relationship for estrogenic flavonoids from Psoralea corylifolia. J Pharm Biomed Anal 161:129-135. https:// doi.org/10.1016/j.jpba.2018.08.040

Zhang C, Chai S, Hao S, Zhang A, Zhu Q, Zhang H, Wang C (2019) Effects of glutamic acid on the production of monacolin $\mathrm{K}$ in four high-yield monacolin K strains in Monascus. Appl Microbiol Biotechnol 103:5301-5310. https://doi.org/10.1007/s00253-019-09752-9

Zheng Y, Zhang Y, Chen D, Chen H, Lin L, Zheng C, Guo Y (2016) Monascus pigment rubropunctatin: a potential dual agent for cancer chemotherapy and phototherapy. J Agric Food Chem 64:2541-2548. https://doi. org/10.1021/acs.jafc.5b05343

\section{Publisher's Note}

Springer Nature remains neutral with regard to jurisdictional claims in published maps and institutional affiliations. 